\title{
Absorption Cross Sections of the ClO Dimer
}

\author{
K. J. Huder and W. B. DeMore* \\ Jet Propulsion Laboratory, California Institute of Technology, Pasadena, California 91109
}

Received: January 10, 1995; In Final Form: February 3, $1995^{\circledR}$

NASA-CR-200336

The absorption cross sections of the $\mathrm{ClO}$ dimer, $\mathrm{ClOOCl}$, are important to the photochemistry of ozone depletion in the Antarctic. In this work new measurements were made of the dimer cross sections at $195 \mathrm{~K}$. The results yield somewhat lower values in the long wavelength region, compared to those currently recommended in the NASA data evaluation (JPL 94-26). The corresponding solar photodissociation rates in the Antarctic are reduced by about $40 \%$.

\section{Introduction}

The $\mathrm{ClO}$ dimer is formed by the self-reaction of $\mathrm{ClO}$ radicals at the low temperatures of the earth's polar winter. When sunlight is present, the dimer is thought to take part in catalytic ozone destruction by yielding chlorine atoms upon photolysis, followed by attack of the chlorine atoms on ozone.

$$
\begin{gathered}
\mathrm{ClOOCl}+h v \rightarrow \mathrm{Cl}+\mathrm{ClOO} \\
\mathrm{ClOO} \rightarrow \mathrm{Cl}+\mathrm{O}_{2} \\
\mathrm{Cl}+\mathrm{O}_{3} \rightarrow \mathrm{ClO}+\mathrm{O}_{2}
\end{gathered}
$$

To model the role of $\mathrm{ClOOCl}$ in polar photochemistry, it is necessary to know its rate of formation, the photolytic cross sections, and the photolysis products. In addition to the path yielding $\mathrm{Cl}$ and $\mathrm{ClOO}$ radicals, another path yielding $\mathrm{ClO}+$ $\mathrm{ClO}$ is possible.

$$
\mathrm{ClOOCl}+h v \rightarrow \mathrm{ClO}+\mathrm{ClO}
$$

This path would not contribute to ozone loss, because ClO is inert to ozone. Although it is normally assumed in atmospheric models that only the $\mathrm{Cl}+\mathrm{ClOO}$ branch is important, the experimental basis for this assumption is somewhat uncertain. Cox and Hayman ${ }^{1}$ concluded that $\mathrm{Cl}$ and $\mathrm{ClOO}$ are the major dimer photolysis products by modeling the disappearance of $\mathrm{Cl}_{2} \mathrm{O}$ and the appearance of dimer in the photolysis of $\mathrm{Cl}_{2} \mathrm{O}$ at $254 \mathrm{~nm}$, at temperatures of $203-233 \mathrm{~K}$. However, they placed an uncertainty of approximately a factor of 2 on the result for the $\mathrm{Cl}+\mathrm{ClOO}$ yield.

In the most direct study at a wavelength appropriate for atmospheric photolysis of the dimer, Molina et al. ${ }^{2}$ reported a quantum yield of approximately unity for the $\mathrm{Cl}+\mathrm{ClOO}$ path at $308 \mathrm{~nm}$. That result was based on measurements of the $\mathrm{Cl}$ atom LIF signal in the photolysis of the dimer ( $235 \mathrm{~K}, 20$ Torr) compared to the $\mathrm{Cl}$ atom LIF signal when photolyzing $\mathrm{Cl}_{2}$ (also at $308 \mathrm{~nm}$ ). However, the authors used a value of 22 for the ratio of the dimer cross sections at 245 and $308 \mathrm{~nm}$, as determined in their own work. If one takes that ratio from the current NASA recommended dimer cross sections, ${ }^{3}$ the value is 13 and the corresponding $\mathrm{Cl}+\mathrm{ClOO}$ quantum yield would be only 0.6 . That would imply that the $\mathrm{ClO}+\mathrm{ClO}$ path makes a $40 \%$ contribution. Thus, there is a direct relationship between the cross sections and the photolysis products.

Eberstein ${ }^{4}$ argued that dimer photolysis should proceed by path (4) on the grounds that the $\mathrm{O}-\mathrm{O}$ bond in $\mathrm{ClOOCl}$ is much

\footnotetext{
${ }^{\otimes}$ Abstract published in Advance ACS Abstracts, March 1, 1995.
}

weaker than the $\mathrm{Cl}-\mathrm{O}$ bond. However, Eberstein assumed that the $\mathrm{Cl}-\mathrm{O}$ bond energy in $\mathrm{ClOOCl}$ is similar to that of the $\mathrm{ClO}$ radical (about $64 \mathrm{kcal} / \mathrm{mol}$ ). Actually, the $\mathrm{Cl}-\mathrm{OOCl}$ bond energy is only about $21 \mathrm{kcal} / \mathrm{mol}$, just slightly greater than the $\mathrm{ClO}-\mathrm{OCl}$ bond $(18 \mathrm{kcal} / \mathrm{mol}){ }^{3}$ Thus, an argument based on preferential breaking of the weaker bond is not compelling in this case.

Previous studies of the dimer spectrum ${ }^{1,5.6}$ (but not that of Molina et al. ${ }^{2}$ ) have used $\mathrm{Cl}_{2} \mathrm{O}$ as the source of $\mathrm{ClOOCl}$. The dimer absorption cross sections are difficult to measure, because the compound is stable only at low temperatures and cannot be prepared in the pure state. The spectrum has only been obtained in the presence of other molecules such as $\mathrm{Cl}_{2}, \mathrm{O}_{3}$, or $\mathrm{Cl}_{2} \mathrm{O}$, and the net $\mathrm{ClOOCl}$ spectrum must be extracted by deconvolution of the composite spectra. This process is somewhat qualitative in nature and is subject to error. The situation is similar to the case of $\mathrm{HOCl}$, for which previous cross section measurements have been erroneous due to contamination with $\mathrm{Cl}_{2} \mathrm{O}$ and $\mathrm{Cl}_{2}{ }^{7}$ Some of the largest cross section errors occur in the "tail" region above $300 \mathrm{~nm}$, where the spectrum is weak. The errors arise from the necessity to correct the spectrum for $\mathrm{Cl}_{2}$ and from base line errors in the total spectrum. This wavelength region is the most important for determining the atmospheric photolysis rates of $\mathrm{ClOOCl}$.

\section{Experimental Section}

Apparatus. The $\mathrm{ClO}$ dimer was prepared as before ${ }^{6}$ by photolysis of $\mathrm{Cl}_{2} \mathrm{O}$ mixtures. The $\mathrm{Cl}_{2} \mathrm{O}$ was produced by oxidation of $\mathrm{Cl}_{2}$ over $\mathrm{HgO}$ at low temperature. ${ }^{8}$ The experiments were performed in a low-temperature, $5 \mathrm{~cm}$ path length spectrophotometric cell of quartz construction. The cell was cooled by a surrounding jacket containing a dry ice/methanol mixture. Some early experiments were performed in a metal cell of similar construction, with halocarbon coating on the walls. However, dimer was found to be more stable in the quartz cell. The cell was evacuated and filled with $\mathrm{Cl}_{2} \mathrm{O}$ at a pressure of about 10 Torr and then pressurized to about $3 \mathrm{~atm}$ with nitrogen to reduce diffusion to the walls. A low-pressure mercury lamp was used for irradiation at $254 \mathrm{~nm}$. The UV absorption spectra were taken from 200 to $400 \mathrm{~nm}$ with a Cary Model 4E spectrometer.

Dimer Spectrum. Since it is difficult to obtain reliable cross sections at longer wavelengths by direct experimental measurement (for reasons discussed above), we have concentrated on obtaining accurate data at shorter wavelengths. Those values can then be used for extrapolation above $310 \mathrm{~nm}$. We have looked only at relative cross sections, since the absolute values 


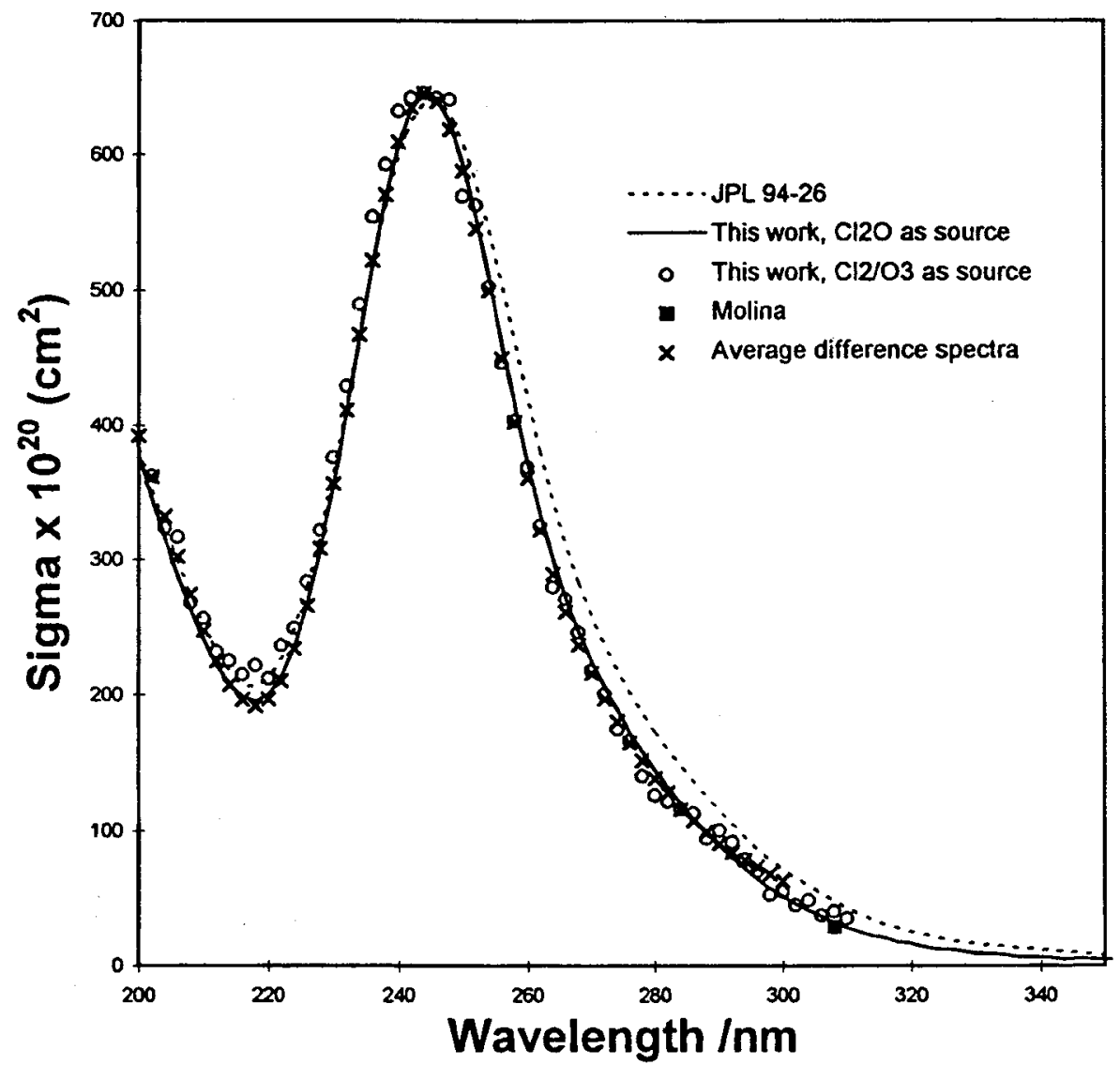

Figure 1. ClOOCl cross sections from this work compared to those of JPL 94-26.

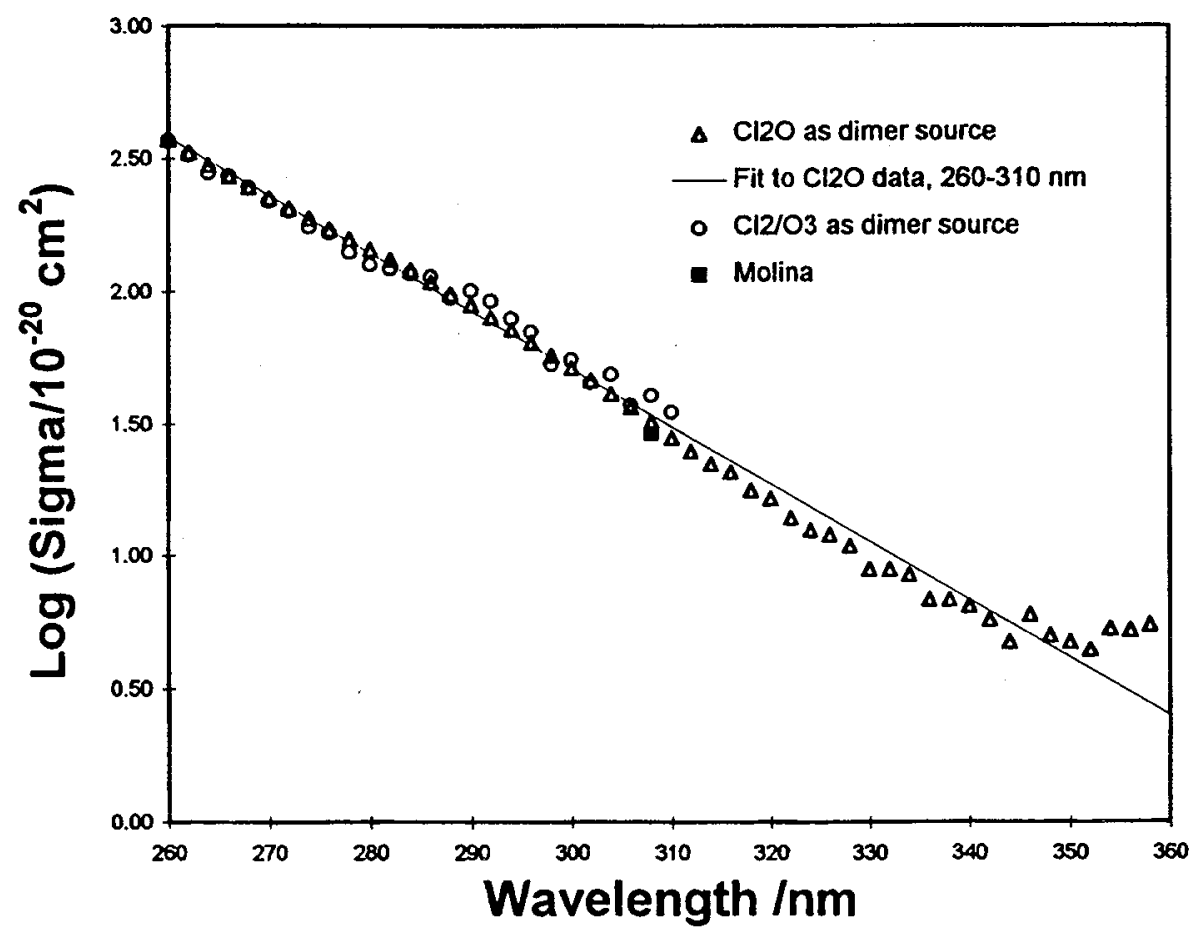

Figure 2. Logarithmic plot of the cross section data.

near the peak are reasonably well established. ${ }^{3}$ The basic problem is to determine how much of the $\mathrm{Cl}_{2} \mathrm{O}$ spectrum to subtract. Three approaches have been used: (1) From the product spectra for each experiment the individual spectra for each component were subtracted from the total spectrum, using the criterion that the peak in the resultant dimer spectrum should be fixed at $244 \mathrm{~nm}$, as determined in earlier work. ${ }^{6}$ (2) Dimer spectra were obtained by taking advantage of the fact that its rate of decomposition in the cell (by wall reactions) is much faster than that of the other components $\left(\mathrm{Cl}_{2} \mathrm{O}\right.$ and $\left.\mathrm{Cl}_{2}\right)$, and thus the dimer spectrum on a relative basis can be obtained by taking difference spectra. The dimer spectrum obtained by the difference method may be slightly contaminated with the $\mathrm{Cl}_{2} \mathrm{O}$ spectrum, to the extent that decomposition of that species occurs 


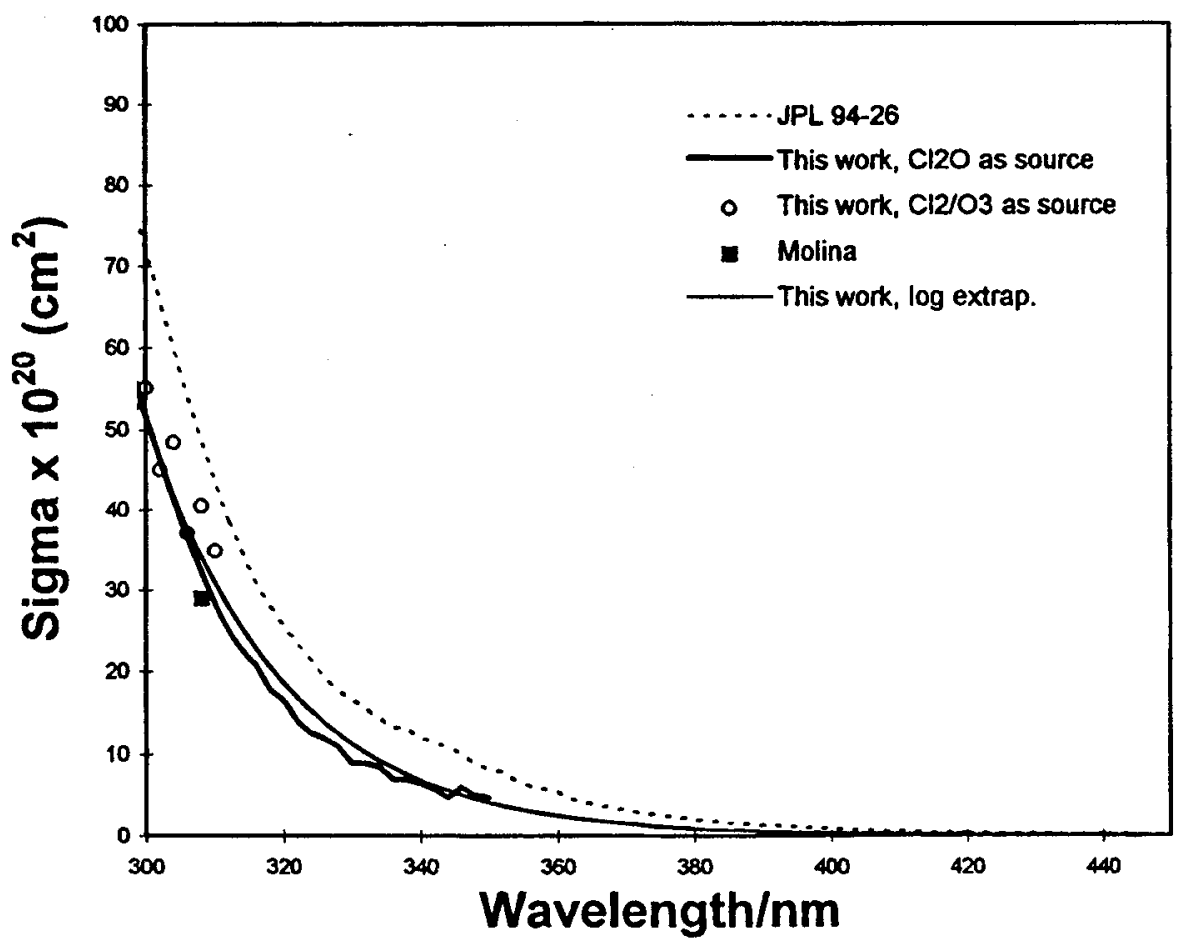

Figure 3. $\mathrm{ClOOCl}$ cross sections at longer wavelengths.

during the time of the dimer decomposition. However, that dimer spectrum should correspond to an upper limit for $\mathrm{Cl}_{2} \mathrm{O}$ content and thus serve as a useful boundary condition for comparison with spectra obtained by the iterative subtraction method. (3) Difference spectra taken in the course of our earlier work, ${ }^{6}$ using $\mathrm{Cl}_{2} / \mathrm{O}_{3}$ mixtures as the dimer source, were compared with the present spectra. The earlier spectra, although less suitable for the measurement of absolute cross sections because of the much lower dimer concentrations, are nevertheless useful for comparison of the shape of the dimer spectrum obtained from the $\mathrm{Cl}_{2} \mathrm{O}$ experiments.

\section{Results}

Figure 1 shows dimer spectra as obtained by methods $1-3$ above. All have been normalized to $6.4 \times 10^{-18} \mathrm{~cm}^{2}$ at 244 $\mathrm{nm}$, this being the JPL $94-26^{9}$ recommendation at that wavelength. The NASA recommendation is included for comparison, as is the single measurement at $308 \mathrm{~nm}$ by the Molina group (calculated from their ratio $\sigma^{245} / \sigma^{308}=22$ ). ${ }^{2}$ Our data are in good agreement among themselves and with the Molina measurement but are significantly lower than the JPL 94-26 recommendation in the tail or falloff region.

Figure 2 is a plot of the logarithms of the cross sections vs wavelength. Also shown is a linear fit to the $\mathrm{Cl}_{2} \mathrm{O}$ data based on the wavelength range $260-310 \mathrm{~nm}$. Above about $310 \mathrm{~nm}$, the logarithmic extrapolation is considered to be a better estimate of the cross sections than the actual data. The extrapolated data are compared in Figure 3 with the data and with the JPL 94-26 recommendation. The latter is based on an extrapolation (above 360 ) $\mathrm{nm}$ of previous data. ${ }^{1,5,6}$ Table 1 lists recommended cross sections based on the present work.

\section{Discussion}

The present results strongly suggest that previous measurements of the dimer cross sections, on which the recommendations in JPL 94-26 (also 92-20) are based, were improperly
TABLE 1: Dimer Cross Sections $\left(\sigma, \mathrm{cm}^{2} \times 10^{20}\right)$

\begin{tabular}{cccccc}
\hline$\lambda, \mathrm{nm}$ & $\sigma$ & $\lambda, \mathrm{nm}$ & $\sigma$ & $\lambda, \mathrm{nm}$ & $\sigma$ \\
\hline 200 & 374.6 & 284 & 119.4 & 368 & 1.7 \\
202 & 342.8 & 286 & 107.9 & 370 & 1.5 \\
204 & 312.8 & 288 & 97.2 & 372 & 1.4 \\
206 & 285.3 & 290 & 88.5 & 374 & 1.2 \\
208 & 260.5 & 292 & 79.5 & 376 & 1.1 \\
210 & 238.3 & 294 & 71.5 & 378 & 1.0 \\
212 & 219.9 & 296 & 63.7 & 380 & 0.92 \\
214 & 205.9 & 298 & 56.9 & 382 & 0.83 \\
216 & 196.7 & 300 & 51.3 & 384 & 0.75 \\
218 & 193.7 & 302 & 46.0 & 386 & 0.68 \\
220 & 198.3 & 304 & 41.6 & 388 & 0.62 \\
222 & 211.5 & 306 & 37.7 & 390 & 0.56 \\
224 & 233.2 & 308 & 34.1 & 392 & 0.50 \\
226 & 264.8 & 310 & 30.8 & 394 & 0.46 \\
228 & 304.7 & 312 & 27.9 & 396 & 0.41 \\
230 & 352.8 & 314 & 25.2 & 398 & 0.37 \\
232 & 406.6 & 316 & 22.8 & 400 & 0.34 \\
234 & 461.6 & 318 & 20.6 & 402 & 0.30 \\
236 & 515.2 & 320 & 18.7 & 404 & 0.28 \\
238 & 563.6 & 322 & 16.9 & 406 & 0.25 \\
240 & 602.4 & 324 & 15.3 & 408 & 0.23 \\
242 & 628.7 & 326 & 13.8 & 410 & 0.20 \\
244 & 640.0 & 328 & 12.5 & 412 & 0.18 \\
246 & 637.1 & 330 & 11.3 & 414 & 0.17 \\
248 & 619.1 & 332 & 10.2 & 416 & 0.15 \\
250 & 588.9 & 334 & 9.2 & 418 & 0.14 \\
252 & 549.5 & 336 & 8.4 & 420 & 0.12 \\
254 & 505.1 & 338 & 7.6 & 422 & 0.11 \\
256 & 458.1 & 340 & 6.8 & 424 & 0.10 \\
258 & 413.0 & 342 & 6.2 & 426 & 0.09 \\
260 & 370.1 & 344 & 5.6 & 428 & 0.08 \\
262 & 332.1 & 346 & 5.1 & 430 & 0.07 \\
264 & 299.0 & 348 & 4.6 & 432 & 0.07 \\
266 & 269.7 & 350 & 4.1 & 434 & 0.06 \\
268 & 245.2 & 352 & 3.7 & 436 & 0.06 \\
270 & 223.3 & 354 & 3.4 & 438 & 0.05 \\
272 & 204.2 & 356 & 3.1 & 440 & 0.05 \\
274 & 187.6 & 358 & 2.8 & 442 & 0.04 \\
276 & 170.9 & 360 & 2.5 & 444 & 0.04 \\
278 & 157.1 & 362 & 2.3 & 446 & 0.03 \\
280 & 143.3 & 364 & 2.1 & 448 & 0.03 \\
282 & 131.0 & 366 & 1.9 & 450 & 0.03
\end{tabular}




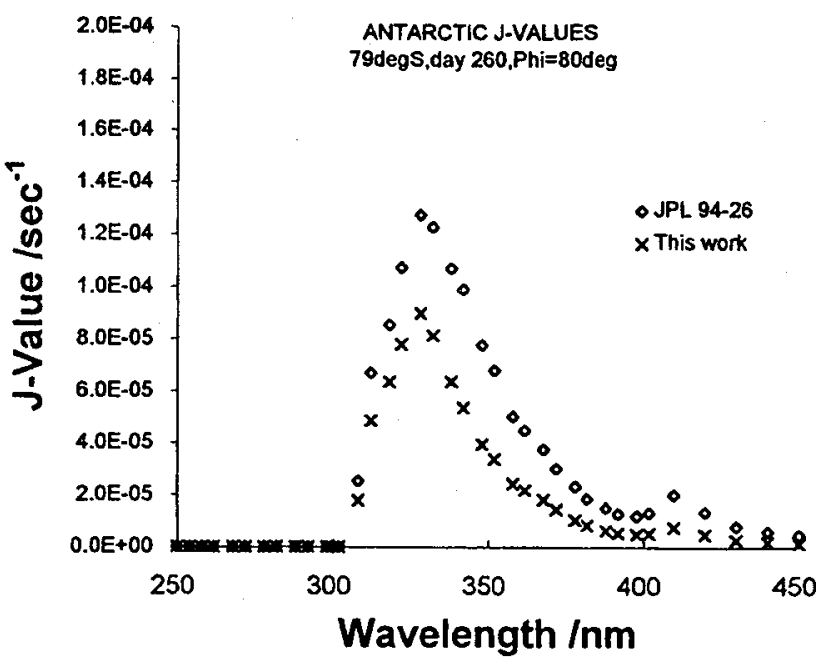

Figure 4. Antarctic $J$ values for $\mathrm{ClOOCl}$.

corrected for $\mathrm{Cl}_{2} \mathrm{O}$ and are too high in the "tail" region. The current results also agree well with the $308 \mathrm{~nm}$ cross section value of the Molina group. ${ }^{2}$ The difference has a significant effect on dimer photolysis rates in the Antarctic atmosphere. Most of the contributions to the photolysis rate occur at wavelengths in the $310-270 \mathrm{~nm}$ range (see Figure 4). With the new cross sections the total $J$ value under Antarctic conditions is about $60 \%$ of that obtained from the JPL 94-26 cross sections. This change will affect the distribution of $\mathrm{ClO}$ between the monomeric and dimeric forms but will not reduce the rate of ozone destruction in the same proportion, because the rate determining step for ozone loss is the $\mathrm{ClO}$ association reaction rather than the photolysis process.

Acknowledgment. The authors are grateful to colleagues at the Jet Propulsion Laboratory for very helpful comments on the paper. K. J. Huder thanks the NRC for a postdoctoral fellowship. Prof. Y. Yung provided a set of solar flux data for the Antarctic $J$ value calculation. This research was carried out by the Jet Propulsion Laboratory, California Institute of Technology, under the contract with the National Aeronautics and Space Administration.

\section{References and Notes}

(1) Cox, R. A.; Hayman, G. D. Nature 1988, 322, 796.

(2) Molina, M. J.; Colussi, A. J.; Molina, L. T.; Schindler, R. N. Chem. Phys. Lett. 1990, 173, 310 .

(3) DeMore, W. B ; Golden, D. M.; Hampson, R. F.; Howard, C. J.; Kolb, C. E.; Kurylo, M. J.; Molina, M. J.; Ravishankara, A. R.; Sander, S. P. Chemical Kinetics and Photochemical Data for Use in Stratospheric Modeling, JPL Publication 92-20; Jet Propulsion Laboratory, California Institute of Technology: Pasadena, CA.

(4) Eberstein, I. J. Geophys. Res. Lett. 1990, 17, 721.

(5) Burkholder, J. B.; Orlando, J. J.; Howard, C. J. J. Phys. Chem. $1990,94,687$. 5856.

(6) DeMore, W. B.; Tschuikow-Roux, E. J. Phys. Chem. 1990, 94,

(7) Burkholder, J. B. J. Geophys. Res. 1993, 98, 2963

(8) Schack, C. J.; Lindahl, C. B. Inorg. Nucl. Chem. Lett. 1967, 3, 387.

(9) DeMore, W. B.; Golden, D. M.; Hampson, R. F.; Howard, C. J.; Kolb, C. E.; Kurylo, M. J.; Molina, M. J.; Ravishankara, A. R.; Sander, S. P. Chemical Kinetics and Photochemical Data for Use in Stratospheric Modeling, JPL Publication 94-26; Jet Propulsion Laboratory, California Institute of Technology: Pasadena, CA.

JP950124B 